Portland State University

PDXScholar

\title{
Effects of Top-Performer Rewards on Fellow Salespeople: A Double-Edged Sword
}

\author{
C. Fred Miao \\ Portland State University, fred.miao@pdx.edu \\ Kenneth R. Evans \\ Lamar University \\ Pochien Li \\ Yuan Ze University
}

Follow this and additional works at: https://pdxscholar.library.pdx.edu/busadmin_fac

Part of the Business Administration, Management, and Operations Commons, and the Sales and Merchandising Commons

Let us know how access to this document benefits you.

\section{Citation Details}

Miao, C. Fred; Evans, Kenneth R.; and Li, Pochien, "Effects of Top-Performer Rewards on Fellow Salespeople: A Double-Edged Sword" (2017). Business Faculty Publications and Presentations. 79. https://pdxscholar.library.pdx.edu/busadmin_fac/79

This Post-Print is brought to you for free and open access. It has been accepted for inclusion in Business Faculty Publications and Presentations by an authorized administrator of PDXScholar. Please contact us if we can make this document more accessible: pdxscholar@pdx.edu. 
Effects of top performer rewards on fellow salespeople: A double-edged sword

\author{
C. Fred Miao, Ph.D.* \\ Assistant Professor of Marketing \\ 660L School of Business Administration \\ Portland State University \\ Portland, OR 97207, USA \\ Telephone: 503-725-3704 \\ Email: fred.miao@pdx.edu \\ Kenneth R. Evans, Ph.D. \\ President and Professor of Marketing \\ Lamar University \\ 4400 MLK Blvd. \\ PO Box 10009 \\ Beaumont, Texas 77710 \\ Email: kevans4@lamar.edu \\ Pochien Li, Ph.D. \\ Associate Professor of Marketing \\ College of Management \\ Yuan Ze University \\ Email: Pochien@saturn.yzu.edu.tw \\ 135 Yuan-Tung Road, Chung-Li Dist. \\ Taoyuan City \\ 32003 Taiwan (R.O.C)
}

*Correspondence author 


\title{
Effects of top performer rewards on fellow salespeople: A double-edged sword
}

\begin{abstract}
Rewarding top performers is of strategic importance to the sales organization. Top performing salespeople not only contribute significantly to the success of their firm but may also motivate the skill development of peer salespeople. However, both academic research and anecdotal evidence suggest that top performer rewards can actually boomerang by damaging peer salespeople's morale and productivity, although the underlying mechanisms and boundary conditions remain unclear. Using a sample of salespeople and their managers from financial investment firms in Taiwan, the authors uncover both positive and negative effects of top performer rewards. Specifically, it is found that when behavior control is employed, top performer rewards are positively associated with perceived top performer customer relationship building competence only when overall organizational justice is high. In contrast, when organizational justice is low and behavior control is employed, top performer rewards give rise to perceived favoritism. Moreover, in large sales units, top performer rewards are much less likely associated with perceived favoritism when organizational justice is high. It is through the perceived top performer customer relationship building competence and perceived favoritism that top performer rewards have a double-edged sword effect on fellow salespeople's selling skills, opportunism, and sales performance. Theoretical and managerial implications are discussed.
\end{abstract}

Key words: top performer rewards; customer relationship building; favoritism; selling skills; opportunism; sales performance 


\section{Introduction}

For many firms, their sales force is the only organizational unit that generates sales revenues and profits (Miao and Evans 2013; Spiro and Weitz 1990). For these organizations, reward systems that recognize and differentiate top performing salespeople from average peers is of strategic importance because top performers (1) contribute significantly to the success of the sales organization (Abosch 2012) and (2) can impart valuable customer relationship building skills to peers (Ledingham, Kovac, and Simon 2006). While most companies consider top performer rewards as strategic investments (Buchanan 2002), some academic researchers have suggested that rewarding top performers can leave other employees demotivated and ready to quit (Pfeffer 2001; Zenger 1992). Anecdotal evidence seems to corroborate these academic insights as it is reported that only one third of such top performer-focused reward programs produced positive results, and about one third even produced negative results, on fellow employees' morale and performance (Cowen 2016). In a similar vein, a Wall Street Journal article (Lehrer 2010) cautions that the so called "star effect" can actually make fellow employees unproductive and less likely to reach their best potential.

While researchers have suggested that top performer rewards hold the potential for altering the behaviors of the observers (e.g., peer salespeople) that reflect either a hopeful or frustrated attitude toward expectancy of performance change (Cowherd and Levine 1992; Schnake and Dumler 1989), the literature is silent on the mechanisms and boundary conditions under which top performer rewards have the intended (positive) vis-à-vis unintended (negative) effects on fellow salespeople's job-related outcomes. Therefore, the current study fills this research gap by explicitly investigating (1) the mechanisms through which top performer rewards have a positive vis-a-vis negative impact on peer salespeople's behaviors and job-related 
outcomes and (2) boundary conditions under which positive or negative outcomes of top performer rewards become particularly salient.

Top performer rewards induce upward comparison made by peer salespeople, which may subsequently alter their expectations of performance change (Cowherd and Levine 1992); hence, expectancy theory (Evans, Margheim, and Schlacter 1982; Vroom 1964) offers valuable insight into the underlying mechanisms that contribute to optimistic or pessimistic reactions by peer salespeople. Our research model (Figure 1) suggests that although top performer rewards strengthen valence of rewards and instrumentality of superior performance, the extent to which top performer rewards produce positive or negative outcomes on fellow salespeople is expected to hinge on expectancy reinforcing (e.g., perceived top performer customer relationship building competence) or expectancy deflating (e.g., perceived favoritism) mechanisms. In particular, when top performer rewards are construed as reflecting the top performer's customer relationship building competence, peer salespeople may have a positive attitude that motivates them to improve their selling skills through peer-based learning, which subsequently enhances performance (Chan, Li, and Pierce 2014). Although salesperson competence can include many other aspects such as product knowledge and presentation skills, we focus on customer relationship building competence because of the pivotal role of customer relationship building in modern marketing exchange (Palmatier et al. 2006). In contrast, when top performer rewards are interpreted as a result of favoritism, peer salespeople may experience reward deprivation resulting in demotivation and subsequent opportunistic behavior (Cowherd and Levine 1992).

Using a dyadic and multi-level dataset of salespeople and their managers from financial investment firms in Taiwan, we empirically test the research framework depicted in Figure 1, results of which provide strong support for most of the hypothesized relationships. We found 
complex three-way cross-level interactive effects of top performer rewards and organizational as well as managerial factors resulting in either positive or negative outcomes on the part of fellow salespeople. Specifically, it is found that when behavior control is employed, top performer rewards are positively associated with perceived top performer customer relationship building competence only when overall organizational justice is high. In contrast, when organizational justice is low and behavior control is employed, top performer rewards give rise to perceived favoritism. Moreover, in large sales units, top performer rewards are much less likely associated with perceived favoritism when organizational justice is high. It is through salesperson perceptions that top performer rewards have indirect effects on their behaviors and sales performance: perceived top performer customer relationship building competence motivates salespeople to improve their selling skills by learning from the top performer (Chan, $\mathrm{Li}$, and Pierce 2014), whereas perceived favoritism induces salesperson opportunistic behavior.

-- Figure 1 about here --

This research makes three important contributions to the sales literature. First, it enriches the literature by uncovering the underlying mechanisms of the double-edged sword effects of top performer rewards, which has been suggested in prior research but never formally investigated. Second, this study also makes a theoretical contribution by illustrating some of the boundary conditions of expectancy theory that can either strengthen or weaken salespeople's expectancy as a function of top performer rewards. Third, our research contributes to sales management practice in that it informs managers of the organizational/managerial factors that can facilitate the intended benefits of top performer rewards while keeping the unintended negative outcomes at bay, which results in significant consequences on the overall effectiveness and productivity of the sales organization (Pfeffer 2001; Schnake and Dumler 1989). 
The remainder of this paper is organized as follows. After a brief review of relevant background literature, we develop detailed hypotheses regarding expected relationships in Figure 1. We then describe our empirical research methods including sample and data collection procedures, measurement validation, data analysis techniques, and hypotheses testing results. We conclude the paper with a discussion of research and managerial implications, limitations of the current study, and directions for future research.

\section{Background literature}

\section{Top performer rewards}

According to a recent report on salary surveys (Abosch 2012), virtually all U.S. organizations consider rewarding their top performing employees a key decision due to the demonstrated link between rewarding top performers and business success. Most sales organizations recognize that top performers expect both tangible (e.g., financial compensation) and intangible (e.g., formal recognition) elements in their rewards as these dimensions bear particular importance to boundary-spanners relative to other employees (Arnold et al. 2009). As top performers in sales organizations typically climb to the top spot as a result of relationship building competence during customer visits and interactions (Gellerman 1990), top performer rewards serve to recognize, differentiate, and retain them as valuable organizational assets (Buchanan 2002).

A less investigated phenomenon is the effect of top performer rewards on fellow salespeople. While some researchers suggest that top performers may help improve fellow salespeople's skills and performance (Chan, Li, and Pierce 2014; Ledingham, Kovac, and Simon 2006), others voice concerns over unintended negative consequences of top performer rewards in terms of peer employee motivation and behavioral reactions (Cowherd \& Levine 1992; Pfeffer 
2001; Zenger 1992). Anecdotal evidence also suggests that rewarding top performers does not always motivate fellow salespeople to perform and that sometimes such reward systems may even have detrimental consequences by damaging peer morale and performance (Cowen 2016; Lehrer 2010). As no academic study has explicitly examined the underlying mechanisms as well as organizational and managerial conditions under which top performer rewards produce positive vis-à-vis negative effects on fellow salespeople's job-related outcomes, an empirical investigation is warranted.

\section{Behavior control}

Sales organizations typically direct their sales force to attain desirable organizational objectives through sales control systems, which are defined as “an organization's set of procedures for monitoring, directing, evaluating, and compensating its employees" (Anderson and Oliver 1987, p. 76). Sales control systems can be primarily outcome-based or behaviorbased, which reflects a continuum of control philosophy and style. When outcome control is employed, salespeople are held accountable for immediate sales results (e.g., sales volume) with very little management involvement in directing or monitoring the process of selling; conversely, behavior-based control is characterized by a high level of managerial involvement in directing and monitoring salesperson activities and/or strategies that management considers necessary in accomplishing desired sales objectives (Oliver and Anderson 1994).

A main benefit of behavior control is the mechanism it affords managers in aligning salesperson behavior with organizational priorities. Under behavior control, the salesperson's financial compensation and career development are largely dependent on fulfillment of required activities during the selling process, which motivates the salesperson to allocate time and effort accordingly (Anderson and Oliver 1987). For example, the company may be interested in 
elevating attention on a particular new product, thereby requiring salespeople to devote a specified amount of effort (e.g., number of sales calls, number of samples distributed, and the kind of promotional materials provided to customers) on behalf of the new product as part of their distribution of selling effort (Ahearne et al. 2010). Similarly, under behavior control, the sales organization can require salespeople to spend more time qualifying new leads than servicing existing customers in order to expand the overall market share (Miao and Evans 2014). Given the alignment of salesperson behavior and organizational objectives, behavior control suggests an appropriate combination of behavioral strategies by which salespeople should organize and engage in their selling activities (Fang, Evans, and Landry 2005).

\section{Organizational justice}

Perceived organizational justice is a necessary condition for the effective functioning of a sales organization (DeConinck and Johnson 2009). Traditionally, organizational justice has been studied as a multi-dimensional construct including distributive justice, procedural justice, and interactional justice (Skarlicki and Folger 1997). While distributive justice is the perceived fairness of rewards allocation, procedural justice refers to the fairness of a company's formal procedures that demonstrate consistency across employees. A third dimension of organizational justice is interactional justice, which focuses on the salesperson's perception of the quality of the interpersonal treatment (e.g., respect and dignity) received during leader-member exchange.

Recent advancement in organizational justice research has questioned the benefits of studying the independent effects of specific types of justice. Focusing on a specific type of justice (e.g., distributive justice) may fail to capture an individual's overall justice judgment, which is a more appropriate variable when examining outcomes such as job performance and attitude toward one's organization. In other words, overall justice is the proximal, whereas 
specific types of justice the distal driver of outcomes (Ambrose and Schminke 2009). In particular, research evidence suggests that people typically form an overall organizational justice judgment and then use this heuristic device (as opposed to individual justice components) to guide their interpretations and responses to organizational events (Bobocel 2013). In other words, what ultimately drives an individual's attitude and behavior is the gestalt of their overall sense of organizational justice, which carries important informational cues and can lead to positive or negative behavioral consequences irrespective of the individual's own outcome favorability such as bonus earned for exceeding quota (Ambrose and Schminke 2009; Barclay, Skarlicki, and Pugh 2005).

\section{Conceptual model overview}

Our conceptual model draws on expectancy theory (Cron, Dubinsky, and Michaels 1988; Vroom 1964), which views the salesperson's motivation as a function of three cognitive components related to a selling task: valence, instrumentality, and expectancy. Valence refers to the salesperson's perceived desirability of receiving increased rewards as a result of improved performance; instrumentality is the perceived linkage between a particular level of performance outcome and corresponding rewards; expectancy reflects an individual's estimate of the probability that expending a certain amount of effort on a task will lead to an improved level of performance.

Consistent with expectancy theory, our model (Figure 1) suggests that top performer rewards (i.e., financial compensation and formal recognition) can elevate the salesperson's perceived valence and instrumentality. However, the extent to which a salesperson will likely strive to improve his/her selling skills (i.e., expectancy) depends on whether the salesperson perceives top performer accomplishments to be a function of customer relationship building 
competence vis-à-vis perceived favoritism. Moreover, the positive effects (i.e., through perceived customer relationship building competence) and the negative influences (i.e., via perceived favoritism) of top performer rewards are moderated by three organizational/managerial factors: behavior control, organizational justice, and unit size. It is in the presence of these boundary conditions that the double-edged sword effects of top performer rewards become particularly salient. We discuss expected relationships of model variables in the next section.

\section{Hypotheses development}

\section{Effects of top performer rewards on salesperson perceptions}

While sales performance is a function of many factors, meta-analytic reviews (e.g., Churchill et al. 1985) suggest that salesperson skill is the most important antecedent of sales performance. Of a salesperson's skill set, customer relationship building competence is a particularly relevant skill because of the strategic importance of cooperative partnerships between the seller and buyer in the modern relationship marketing era (Hunter and Perreault 2007; Palmatier et al. 2006). Superior performance (e.g., large orders) is often the result of a strong relationship cultivated between the salesperson and the customer (Gellerman 1990). In fact, a strong salesperson-customer relationship not only directly improves salesperson performance, but also enhances customer loyalty toward the selling firm leading to higher customer share, price premium, and sales growth (Palmatier et al. 2007).

Moreover, many sales organizations also define a new role for their top salespeople as collegial mentors such that what appears to be instinctual relationship-building skills can be imparted (Ledingham, Kovac, and Simon 2006). By observing first-hand the top performer's customer-winning strategy and behavior, salespeople can strengthen the perceived link of customer relationship building competence and superior performance (i.e., expectancy 
reinforcing), especially in a work environment where salespeople operate in close proximity (e.g., retailing) so interaction with and feedback from the top performer is likely (Chan, $\mathrm{Li}$, and Pierce 2014). To the extent that top performer rewards reflect superior customer-driven sales performance, salespeople will perceive a positive relationship between top performer rewards and top performer customer relationship building competence.

$\mathrm{H}_{1}$ : There is a positive association of top performer rewards and perceived top performer customer relationship building competence.

When the sales organization employs a high level of behavior control, however, the positive association of top performer rewards and perceived top performer customer relationship building competence will be weaker. Under behavior control, the sales organization prescribes a set of instrumental behavior-based requirements (e.g., following a predetermined procedure for handling customer objections) that salespeople must perform, as attainment of these behavioral goals is assumed to eventually lead to successful sales results (Miao and Evans 2013; Oliver and Anderson 1994). Although some required activities (e.g., prioritizing new customer visits over providing service to existing customers) may not be conducive to customer relationship building, in principle every salesperson (including the top performer) will have to perform the sales task in a similar fashion according to prescribed standard procedures and steps, because behavior control empowers the manager to guide and monitor the way salespeople carry out tasks (Oliver and Anderson 1994). Because performance evaluation under behavior control focuses on the salesperson's inputs (e.g., activities) as opposed to immediate outputs (e.g., sales volume) during the selling process (Oliver and Anderson 1995), efficiency in carrying out required activities becomes particularly important. That is, individual differences in customer relationship building competence become somewhat less impactful, as long as the "recipe" of selling is carried out efficiently. 
$\mathrm{H}_{2 \mathrm{a}}$ : Behavior control weakens the positive association of top performer rewards and perceived top performer customer relationship building competence.

Academic research suggests that companies have a general tendency to treat top performers' deviant behavior more leniently (Bellizzi and Bristol 2005). Because top performers interact more frequently with the manager and typically have a closer relationship with the top management (Lam, Kraus, and Ahearne 2010), the sales force at large may perceive that top performers have gained an unfair advantage from these favored relationships otherwise not available to the rank and file, whether or not perceived favoritism actually has occurred (Henderson 2001). Anecdotal evidence also indicates that it is not uncommon that managers demonstrate favoritism toward their top salesperson over fellow salespeople (Offenberger 2016). The positive association of top performer rewards and perceived favoritism may be especially strong when behavior control is employed. This is because behavior control gives rise to potentially biased managerial discretion in the selling process (e.g., rule bending) or resource allocation decisions (e.g., better customers) favoring the top performer (Ahearne et al. 2010; Offenberger 2016), which may have a detrimental effect on the salesperson's (non-top performer) future expectancy. While certainly perceived favoritism may not be reflected in reality, individuals will "ultimately act in accordance with inferences made" (Teas and McElroy 1986, p.76). As such, we expect a positive association of top performer rewards and perceived favoritism, which becomes stronger when there is a high level of behavior control.

$\mathrm{H}_{2 \mathrm{~b}}$ : There is a positive association of top performer rewards and perceived favoritism. $\mathrm{H}_{2 \mathrm{c}}$ : When behavior control is employed, the positive association of top performer rewards and perceived favoritism is stronger.

Most sales organizations employ some degree of behavior control (Miao and Evans 2013; Oliver and Anderson 1994); hence, a relevant question is under what conditions can the detrimental effects of behavior control be suppressed? We believe that organizational justice 
research provides important insight into how salespeople perceive their work environment, which, in turn, will influence their beliefs about rewards and overall expectancy within the organization (Tyagi 1982). Behavior control is typified by a high level of standardized selling activities under frequent supervisor monitoring, direction, and intervention resulting in sales organizations obtaining a great deal of discretion in terms of input decision (e.g., resource allocation) and subjective performance evaluation (Oliver and Anderson 1994); however, it is this subjective characteristic of behavioral control that may give rise to either real or perceived preferential treatment toward top performers (Offenberger 2016). As such, salespeople may have drastically different interpretations of the nature and role of the behavior control within their sales organizations, which can subsequently alter their behavioral responses. Within the context of this study, we expect that when there are high levels of overall organizational justice, salespeople will tend to trust management to implement behavior control fairly and consistently across all employees (including the top performers). Should this be the case, we conjecture there will be less concern that the top performers have been provided unfair advantages (e.g., better sales territories). Moreover, it is anticipated that top performers will be evaluated by the same criteria used for assessing other salespeople (e.g., no rule bending when performing required selling activities). Consequently, when overall organizational justice is high, we anticipate that the standardized nature (i.e., same requirements and procedures) of behavior control can become a dominant feature providing a fair evaluation platform. When organizational justice is low, however, concerns over the subjective and discretionary nature of behavior control loom large, which fuels suspicion that the top performer may be provided an unfair advantage over peer salespeople. In such instances, procedural or interactional justice is believed to be violated, regardless of the salesperson's own outcome favorability (Aquino, Tripp, and Bies 2006; 
Barclay, Skarlicki, and Pugh 2005). As such, we hypothesize that organizational justice can alter the perceived nature of behavior control and its moderation effects in the following fashion:

$\mathrm{H}_{3 \mathrm{a}}$ : There is a three-way interaction among top performer rewards, behavior control, and overall organizational justice such that only when organizational justice is low will behavior control significantly weaken the positive association of top performer rewards and perceived top performer customer relationship building competence.

$\mathrm{H}_{3 \mathrm{~b}}$ : There is a three-way interaction among top performer rewards, behavior control, and overall organizational justice such that only when organizational justice is low will behavior control significantly strengthen the positive relationship of top performer rewards and perceived favoritism.

Sales unit size is another boundary condition in our model, because research has shown that unit size provides important contextual information for decision making (Desai 2015), impacts inferences made (Green and Peloza 2014), and alters the attributional process (Huber, Podsakoff, and Todor 1986), all of which can affect the salesperson's expectancy in the context of this study. In instances where the sales unit is large, the sales role may be laden with more ambiguity and uncertainty especially in relation to what may have accounted for the top performer's performance (Arnold et al. 2009).

We suggest that the overall justice perception provides a pivotal mental shortcut through which inferences can be made (Bobocel 2013). On the one hand, a large sales unit typically has more intense intra-unit competition among salespeople, where a top performer may likely be considered even more competent in customer relationship building. Conversely, a large sales unit is also more likely to have uneven resource allocations (e.g., customer accounts of different quality or potential). Territory and customer difficulty may remain hard to determine at the individual salesperson level (Arnold et al. 2009). This may result in large sales unit size giving rise to perceptions of unfair advantage for the top performer over others simply because of the 
difficulty in being fully informed about how sales colleagues are presented opportunities and resources.

Therefore, the extent to which salespeople will attribute the top performer's rewards to competence versus favoritism can be affected by the relative size of the sales unit with larger units creating more opportunities for mixed messages in overall justice perceptions (Arnold et al. 2009). When overall organizational justice is high, salespeople will have a higher level of confidence in the integrity of the sales-related decisions regarding the extent to which similar resource allocation decisions and procedural requirements are applied across the sales force. Consequently, in a large sales unit salespeople will more likely perceive top performer rewards as a function of superior customer relationship building competence given more intense intraunit competition. Conversely, when organizational justice is low, salespeople in a large sales unit are more likely to perceive unfair treatment in favor of the top performer due to greater potential variation in resource allocations and managerial discretion.

$\mathrm{H}_{4}$ : There is a three-way interaction among top performer rewards, sales unit size, and overall organizational justice such that when organizational justice is high, a large sales unit size (a) strengthens the positive association of top performer rewards and perceived top performer customer relationship building competence and (b) weakens the positive relationship of top performer rewards and perceived favoritism.

\section{Effects of salesperson perceptions on outcomes}

Perceived top performer customer relationship building competence and perceived favoritism can affect salespeople's future expectancy beliefs in an opposite fashion, which ultimately result in considerably different behavioral responses (Johnston and Kim 1994; Teas and McElroy 1986). In particular, perceived top performer customer relationship building competence can motivate the salesperson to improve his/her selling skills. Research suggests that the top performer (i.e., peer expert) has a significant positive influence on fellow salespeople via 
a role modeling process where salespeople will learn through the peer expert (Lam, Kraus, and Ahearne 2010). Similarly, in a retail setting, Chan, Li, and Pierce (2014) demonstrate that retail salespeople can effectively improve their selling abilities over time through observing and learning from the top performer in their work unit, thereby enhancing future expectancy of sales productivity. Importantly, such peer-based learning is effective not only for new salespeople but also for experienced salespeople when working with top sales performers (Chan, Li, and Pierce 2014). Sales management in practice reinforces this argument where sales organizations are reported to encourage salespeople to develop/enhance their customer relationship building skills by observing firsthand how the high-performing salespeople worked (Ledingham, Kovac, and Simon). Therefore, we expect a positive impact of perceived top performer customer relationship building competence on the salesperson's selling skills.

$\mathrm{H}_{5 \mathrm{a}}$ : There is a positive association of perceived top performer customer relationship building competence and the salesperson's selling skills.

While we expect a positive relationship of perceived top performer customer relationship building competence and the salesperson's selling skills, this positive effect will likely be weakened by a high level of behavior control. This is because under behavior control salespeople must follow a prescribed set of activities when fulfilling selling tasks, which can significantly diminish a salesperson's ability to adapt to a variety of situations where different customer strategies or skills are appropriate (Ahearne et al. 2010). For example, under behavior control the salesperson may be required to sell a high profit margin product to new customers, when it is more appropriate to focus on other products in dealing with certain types of customers (Miao and Evans 2013). Consequently, while behavior control is otherwise well-intended, it can limit salespeople's flexibility in practicing knowledge uniquely learned from and attributed to the top 
performer during customer interactions, which can compromise the advancement of selling skills.

$\mathrm{H}_{5 b}$ : The positive association of perceived top performer customer relationship building competence and the salesperson's selling skills is weaker when there is a high level of behavior control.

The marketing literature has long established that selling skills are a pivotal precursor of salesperson performance (Pullins and Fine 2002; Sujan, Weitz, and Sujan 1988). In their seminal meta-analytic study, Churchill and colleagues (1985) found that selling skills are the most important determinant of the salesperson's performance after accounting for individual demographic variables. More recent studies suggest that customer-directed selling skills such as closing sales are strongly related to the salesperson self-reported performance (Plouffe, Hulland, and Wachner 2009; Rentz et al. 2002). Therefore, salesperson's selling skills are expected to have a positive effect on salesperson performance as evaluated by their managers.

$\mathrm{H}_{6}$ : Salesperson's selling skills are positively associated with salesperson performance as evaluated by their manager.

The boundary-spanning nature of the sales job can readily give rise to negative salesperson behavior because it is not uncommon for salespeople to misbehave as a reaction to perceived unfair organizational actions (Barclay, Skarlicki, and Pugh 2005; Choi, Dixon, and Jung 2004; Jelinek and Ahearne 2006). In particular, perceived favoritism dampens salesperson expectancies suggesting to the salesperson that perceived top performer customer relationship building competence may not be the main driver of performance and subsequent rewards. Instead, the top performer is perceived as potentially gaining an unfair advantage, which suggests an unevenness in the work environment and motivates the salesperson to "balance the scale" by engaging in opportunistic behavior such as "smoothing, focusing, and invalid data reporting" (Ramaswami and Singh 2003, p. 54) 
Research in social psychology also illustrates that unfair treatment (e.g., perceived favoritism) may result in employees taking justice into their own hands by seeking revenge or trying to get even, which is likely fueled by outward-focused negative emotions such as anger (Aquino, Tripp, and Bies 2006; Barclay, Skarlicki, and Pugh 2005). Therefore, we expect perceived favoritism to increase salesperson opportunism.

$\mathrm{H}_{7}$ : Salesperson's perceived favoritism received by the top performer is positively related to salesperson opportunism.

\section{Research methods}

\section{Sample and data collection}

We collected dyadic and multi-level data from salespeople and their managers within the consumer sales divisions of financial investment firms in Taiwan. This empirical setting is appropriate because (1) all the salespeople work on site in the same branch as opposed to working in different territories outside the firm so peer-based learning is more likely and (2) salespeople are incentivized by commissions making it possible for a salesperson to expect a higher income should performance improve (i.e., future expectancy). After contacting over a dozen financial firms, a total of nine firms agreed to participate in this research. The original English survey was translated by two bilingual researchers following the conventional translation-back translation procedure to create the Chinese version for data collection (Brislin 1980).

The surveys were distributed by one of the authors' research assistants who brought questionnaire materials to the sales executives in person. Sales executives were given a research briefing before they delivered the survey materials to their sales managers. Sales managers then distributed survey materials to their salespeople, following a brief meeting with their sales executives. Sales managers were instructed to distribute the salesperson surveys to three salespeople they directly supervised (none of which was the top performer). Sales research 
indicates that the top performer is typically widely recognized in the workplace so salespeople were not expected to have a problem identifying the top performer in their respective sales unit (Lam, Kraus, and Ahearne 2010). Although there could be more than one top performer in the sales unit, the focus of this study is on the impact of that top performer's rewards on the salesperson's job-related outcomes without regard to who the top performer is.

To encourage response rate, the nine sales executives were promised a copy of the research findings with managerial implications, and salespeople and sales managers were guaranteed anonymity. Moreover, no names were included on the surveys. Instead, surveys were coded in a way that permitted researchers to link salespeople to their managers upon completion of the data collection. A week after the distribution of the surveys, a follow-up call was made to each of the nine sales executives by research assistants. Two weeks after the distribution of surveys, research assistants collected completed questionnaires directly from the salespeople and their managers so salespeople's responses would not be revealed to their sales managers. Because of the strong interest and endorsement of the sales executives, of the 83 sales managers and 249 salespeople who received surveys, we were able to match 71 completed surveys from sales managers (effective response rate of 86\%) with 212 completed questionnaires from the salespeople (effective response rate of $85 \%$ ). Roughly half of the responding salespeople were male (49.5\%), and the average age of the salespeople was 35 years old with a mean fulltime sales experience of almost 7 years.

\section{Study measures}

Whenever possible, we adapted existing scales from the literature to operationalize variables in our study. All multi-item measures were anchored on a 7-point Likert scale. On the salesperson's survey, top performer rewards $(\alpha=.76)$ was measured with two items that capture the salesperson's perceived financial compensation and formal recognition the top performer 
received (Arnold et al. 2009). Perceived top performer customer relationship building competence $(\alpha=.83)$ was measured with five items that are manifestations of the top performer's customer relationship forging skills (Hunter and Perreault 2007). A three-item scale for perceived favoritism ( $\alpha=.93$ ) was developed for this study, which assessed the salesperson's perception of the extent to which unfair advantage was given to the top performer in resource allocation (e.g., customer accounts assignment). Overall organizational justice $(\alpha=.73)$ was assessed with four items from Ambrose and Schminke (2009) that evaluate the salesperson's general perception of how fairly the company treats its employees. We measured the salesperson's selling skills ( $\alpha=.92)$ with three items from Plouffe, Hulland, and Wachner (2009) that evaluate the salesperson's ability to prospect and qualify leads as well as to close sales. Salesperson opportunism ( $\alpha=.83)$ was assessed with four items adapted from Ramaswami and Singh (2003) that indicate the salesperson's data "managing" effort in creating favorable impressions and evaluations. Sales managers provided data regarding behavior control, sales unit size, and salesperson performance evaluations. Specifically, behavior control $(\alpha=.71)$ was assessed with two items adapted from Cravens et al. (1993) tapping the extent to which the sales manager was actively involved in directing and monitoring salespeople's activities during the selling process. Salesperson performance $(\alpha=.92)$ was measured with three items adapted from Cravens et al. (1993) that assessed the salesperson's contribution to sales revenues and profits. Moreover, managers reported sales unit size by providing the total number of salespeople working in the same unit.

We also included three control variables-the salesperson's own rewards, age, and fulltime sales experience-as these variables may affect the salesperson's perceptions and/or performance (Churchill et al. 1985; Johnston and Kim 1994). Salesperson's own rewards 
( $\alpha=.86)$ was measured with two items adapted from Arnold et al. (2009) in terms of the salesperson's own financial compensation and recognition received, and salesperson age and sales experience were each measured with a single item in number of years.

\section{Measurement model}

We assessed the psychometric properties of the multi-item constructs with confirmatory factor analysis (CFA) using EQS 6.1 software. The CFA model demonstrates an acceptable fit: $\chi^{2}{ }_{(314)}=558.79, p<.01 ; \mathrm{IFI}=.94, \mathrm{CFI}=.94, \mathrm{RMSEA}=.06$. All item loadings were large, positive and significant on their a priori constructs, demonstrating convergent validity (Anderson and Gerbing 1988). We next assessed discriminant validity in two ways. First, the average variance extracted (AVE) for each construct exceeds its squared correlation with all other constructs, suggesting discriminant validity (Fornell and Larcker 1981). Second, we also conducted Chi-square difference tests for all possible pairs of constructs comparing a one-factor model with a two-factor model. In all cases the two-factor model fit the data significantly better than the one-factor model $(\mathrm{p}<.01)$. Therefore, acceptable psychometric properties for all multiitem constructs were established. In Table 1, we present the descriptive statistics of all study variables.

-- Table 1 about here --

Because level-one data (with the exception of salesperson performance) all came from the same source-the salesperson, we tested potential common method variance (CMV) using two methods. First, we estimated a Harmon's single factor where all items loaded on a single construct. This model had a much worse fit than our nine-factor measurement model $\left(\Delta \chi^{2}(\mathrm{df}=36)=\right.$ $2422.705, p<.01$ ), suggesting there is no single common factor. Second, we included a common method factor on which all items loaded and re-estimated an overall measurement model. It was 
found that trait variance (average 79.3\%) significantly exceeds method variance (average 6.6\%) and error variance (average 14.1\%). The magnitude of average method variance is small and comparable with those reported in other similar studies (Carson 2007; Kim, Cavusgil, and Calantone 2006). Moreover, because our empirical test involves complex two-way and threeway interactions, which cannot be artifacts of CMV (Siemsen, Roth, and Oliveira 2010), we conclude that common method bias is not likely a serious concern in this study.

\section{Analytical strategy}

As mentioned earlier, data came from two levels: salespeople (level-one) and their managers (level-two). Salespeople within the same unit are nested under their manager. Therefore, the multi-level structure of the data lends itself to a two-level structural path model approach. We employed Mplus 7 for the simultaneous testing of all structural relationships depicted in our conceptual model, which is superior to other multi-level packages such as the HLM software which can only test one dependent variable at a time.

We standardized all factor scores throughout the model before creating interactive terms (Hughes, Bon, and Rapp 2013). Because standard fit indices are not available in Mplus when estimating cross-level interactive effects, the deviance (-2 log-likelihood criterion) between the nested models is compared with a chi-square distribution with the degrees of freedom equal to the difference in the number of parameters between the two models. A significant Chi-square difference will indicate model fit improvement.

\section{Hypotheses testing results}

To test the hypotheses, a series of nested models were estimated (See Table 2). First, we estimated a baseline model that included only the main effects of level-one and level-two variables without entering the interactive effects (Model 1). Next, in Model 2, we entered 
hypothesized two-way and three-way interactive terms. This hypothesized model demonstrated a substantial improvement over Model 1 with a significant Chi-square difference $(\mathrm{p}<.01)$. We report hypotheses testing results based on Model 2. Table 2 presents detailed hypothesis testing results.

-- Table 2 about here --

$\mathrm{H}_{1}$ predicts a positive relationship of top performer rewards and perceived top performer customer relationship building competence, which is supported $(\mathrm{b}=.42, \mathrm{p}<.01)$. This main effect suggests that in general, salespeople consider top performer rewards as a function of superior competence in forging strong customer relationships. $\mathrm{H}_{2 \mathrm{a}}$, however, suggests that this positive effect is weakened when a high level of behavior control is employed. The cross-level interaction of behavior control (level-two) and top performer rewards (level-one) is indeed negative and significant $(b=-.17, \mathrm{p}<.05)$, in support of $\mathrm{H}_{2 \mathrm{a}}$. Top performer rewards have a positive yet nonsignificant effect on perceived favoritism ( $b=.07$, n.s.), which rejects $\mathrm{H}_{2 \mathrm{~b}}$. The interaction of behavior control and top performer rewards on perceived favoritism is not significant $(b=.01$, n.s.); therefore, $\mathrm{H}_{2 \mathrm{c}}$ is rejected. These two-way interactions are further influenced by the third variable-overall perceived organizational justice. As $\mathrm{H}_{3 \mathrm{a}}$ predicts, overall perceived organizational justice, behavior control, and top performer rewards have a three-way interaction such that behavior control weakens the positive effect of top performer rewards on perceived customer relationship building competence only when overall organizational justice is low. It is found that the three-way interaction indeed has a positive effect $(b=.09, p<.05)$, in support of $\mathrm{H}_{3 a}$. Figure 2 (panel A) illustrates that, when salespeople perceive a low level of overall organizational justice (one standard deviation below the mean), the more behavior control is employed, the weaker the link of top performer rewards and perceived customer relationship 
building competence. Conversely, when overall organizational justice is high (one standard deviation above the mean), the influence of behavior control is much weaker. $\mathrm{H}_{3 \mathrm{~b}}$ is also supported because the three-way interactive effect of top performer rewards, behavior control, and organizational justice on perceived favoritism is negative and significant $(b=-.14, p<.05)$. As Figure 2 (panel B) indicates, under a high level of behavior control, top performer rewards will lead to perceived favoritism only when overall organizational justice is low; when overall organizational justice is high, top performer rewards actually lead to a lower level of perceived favoritism under a high level of behavior control. $\mathrm{H}_{4 \mathrm{a}}$ is not supported as the three-way interactive effect on perceived customer relationship building competence of top performer rewards, sales unit size, and organizational justice is not significant ( $b=.05$, n.s.). However, the three-way interactive effect on perceived favoritism is negative and significant $(b=-.14, p<.01)$, in support of $\mathrm{H}_{4 \mathrm{~b}}$. Figure 2 (panel C) suggests that under low overall organizational justice, high top performer rewards lead to higher perceived favoritism in large sales units; in contrast, under high overall organizational justice, high top performer rewards actually lead to lower perceived favoritism in large sales units.

$\mathrm{H}_{5 \mathrm{a}}$ is supported as perceived top performer customer relationship building competence has a positive effect on salesperson selling skills $(b=.23, p<.01)$. The interactive effect of behavior control and perceived top performer customer relationship building competence on salesperson selling skills is negative and significant $(b=-.12, p<.05)$, in support of $\mathrm{H}_{5 \mathrm{~b}}$. As Figure 2 (panel D) illustrates, when there is a high level of behavior control, the positive association of perceived top performer customer relationship building competence and salesperson selling skills is much weaker. Salesperson selling skills have a positive effect on 
manager-rated salesperson performance $(\mathrm{b}=.22, \mathrm{p}<.01)$, and perceived favoritism has a positive effect on salesperson opportunism $(b=.28, \mathrm{p}<.01)$. Therefore, $\mathrm{H}_{6}$ and $\mathrm{H}_{7}$ are both supported.

-- Figure 2 about here --

Finally, we tested relationships not hypothesized in the conceptual model (e.g., direct effect of top performer rewards on salesperson performance), one at a time in Model 3 (best fitting model as illustrated in Table 2). It was found that this model shows an improvement in fit compared to our hypothesized model $(\mathrm{p}<.01)$. Three additional significant paths were added: behavior control has a positive effect on salesperson opportunism $(b=.10, \mathrm{p}<.05)$, sales unit size has a negative effect on salesperson selling skills $(b=-.06, p<.05)$, and overall organizational justice perception suppresses salesperson opportunism $(b=-.35, p<.01)$. Importantly, with the additional paths, all but one (i.e., the path from overall organizational justice to perceived favoritism) of the significant relationships found in Model 2 remain statistically significant. As no direct path from top performer rewards is significant, the effects of top performer rewards on salesperson selling skills, opportunism, and sales performance appear to be indirect through the salesperson's perceptions.

\section{Discussion}

\section{Theoretical implications}

As sales organizations invest more financial resources and time on their strategic assetthe sales force-in the highly competitive marketplace, retaining top performers has taken on an increasingly pivotal role. Rewarding the top performer through attractive financial incentives and formal recognition is critical to the sales organization's success (Buchanan 2002; Cowherd and Levine 1992), and the top performer is also expected to have a positive effect on fellow salespeople's skills through peer-based learning (Chan, Li, and Pierce 2014; Ledingham, Kovac, 
and Simon 2006). However, anecdotal evidence has indicated that rewarding the top performers does not always result in positive outcomes on fellow employees' morale or performance and often can have contradictory implications (Cowen 2016; Lehrer 2010).

Academic research suggests that top performer rewards may have unintended negative consequences on the health of the sales organization as peer salespeople may experience deprivation (Cowherd and Levine 1992) and become demotivated (Pfeffer 2001). An understanding of how and when to utilize top performer rewards and their possible positive versus negative effects on peer salespeople, however, is still lacking. This study makes an important contribution to the literature by uncovering the underlying mechanisms as well as the boundary conditions responsible for the positive vis-à-vis negative effects of top performer rewards. By illustrating the contingent effects of top performer rewards on the salesperson's perceptions (i.e., expectancy reinforcing or destroying), this study shows that top performer rewards are indeed a double-edged sword capable of producing both positive and negative consequences on the part of fellow salespeople.

From a theoretical perspective, this study suggests that understanding the mechanisms through which the double-edged sword effects of top performer rewards operate requires consideration of the boundary conditions of expectancy theory. According to expectancy theory (Vroom 1964), a high level of top performer rewards can elevate fellow salespeople's perceived valence and instrumentality of superior performance. However, top performer rewards will not always motivate salespeople to improve their selling skills (i.e., expectancy). Whether salespeople are motivated to improve their skills by learning from the top performer is still dependent on the extent to which salespeople consider top performers' rewards as a function of customer relationship building competence. The perceived link of top performer rewards and 
customer relationship building competence can have a reinforcing effect on the salesperson's own future expectancy belief that improved skills will lead to better performance and handsome rewards.

While it appears that there is generally a positive association of top performer rewards and perceived top performer customer relationship building competence, boundary conditions can affect the strength of this relationship. Most sales organizations employ behavior control to some degree because it affords managers the ability to direct and influence salespeople's selling process in accordance with the sales organization's goals and objectives (Anderson and Oliver 1987). However, when the sales organization employs a high level of behavior control, we find that the positive association of top performer rewards and perceived top performer customer relationship building competence is much weaker. Under behavior control, salespeople carry out tasks by performing required selling activities and strategies that are deemed instrumental to meeting organizational objectives (Oliver and Anderson 1994). For example, the sales organization may require salespeople to allocate most of their time and effort on a high-profit new product, which may often distract from broader based need analysis and run counter to the principles of customer orientation and relationship building (Saxe and Weitz 1982). Therefore, under behavior control, efficiency in carrying out required activities may be more important than customer relationship building competence per se. Moreover, because resource allocation and performance evaluations under behavior control are subjective in nature (Ahearne et al. 2010; Oliver and Anderson 1994), opportunities for the introduction of interpersonal biases such as favoritism are more prevalent (Bellizzi and Bristol 2005; Lam, Kraus, and Ahearne 2010), which can dampen the salesperson's future expectancy. Therefore, the perceived dominant nature of 
behavior control (i.e., standardized behavioral requirements vs. subjective biases) will determine its moderation effects.

Overall organizational justice becomes a critical environmental factor that can alter the salesperson's expectancy when behavior control is employed. Overall justice perception is a function of salespeople's global assessment of fairness in the sales organization, which is a heuristic cue used to judge events of potentially significant consequences (Bobocel 2013). In other words, overall justice judgment can shape salespeople's cognitive perceptions of causal relationships, which, in turn, determine their attitudes and behaviors (Ambrose and Schminke 2009; Bobocel 2013). When salespeople believe that the organization treats its employees fairly, an overall justice perception is formed, which enhances their confidence that the organization will treat them in the same fashion as that of a top performer. This belief significantly minimizes concerns of subjective biases in favor of the top performers under behavior control. For example, when the salesperson feels confident that the top performer is not selectively allocated top prospects (i.e., equal assignment playing field), a positive association of top performer rewards and perceived top performer customer relationship building competence will likely remain significant under behavior control. Indeed, our results suggest that only when overall justice is high will the detrimental moderation effect of behavior control be mitigated. In contrast, when overall justice is low and behavior control is employed, salespeople are much more likely to perceive top performer rewards as a result of perceived favoritism, as they may not be confident in the organization's integrity in equally enforcing behavior control across salespeople.

Similarly, when the sales unit is large (i.e., more salespeople), it becomes more difficult for the salesperson to observe and monitor a more expansive environment. On the one hand, in a large sales unit there is typically more intra-unit competition, which would corroborate the top 
performer's competence; on the other hand, a large sales unit also typically has more resources at its disposal, which can give rise to perceived favoritism in resource allocation and support decisions. As a result, the salesperson will likely rely on the overall justice perception as a heuristic shortcut to make inferences (Bobocel 2013). Indeed, our results suggest that only when overall organizational justice is high will top performer rewards be less likely associated with perceived favoritism in large sales units.

Perceived top performer customer relationship building competence reinforces the salesperson's expectancy that improved customer-directed skills will lead to consistently better future sales outcomes. This, in turn, will motivate peer-based learning as the salesperson actively learns from the top performer for skill improvement (Chan, Li, and Pierce 2014). Although skills and competence are relatively stable, they do evolve over time through learning by observation and doing (Ledingham, Kovac, and Simon 2006). Our results are consistent with the extant literature indicating that perceived top performer customer relationship building competence is positively related to salesperson selling skills, which subsequently leads to higher levels of sales performance. A caveat is that behavior control may hamper the peer-based learning process because it restricts the salesperson's flexibility in adapting to customers' divergent needs. For example, different customers need to be handled with different strategies when it comes to overcoming customer objections. The standard procedures required under behavior control would make it difficult for salespeople to effectively adapt to unique customer relational needs (Miao and Evans 2013), thereby impeding the flexibility necessary to practice skills acquired during peer-based learning from top performers.

Perceived favoritism is expectancy damaging due to the presumed unfair advantage of the top performer over peers. It has been suggested that perceived unfairness in the workplace can 
lead to employee deviant behavior or opportunism justified due to the presumed inequity (Ramaswami and Singh 2003). When salespeople suspect that work related unfair actions (e.g., perceived favoritism) have occurred, they can experience strong negative emotions such as anger toward the management, which can induce retaliation toward the organization (Barclay, Skarlicki, and Pugh 2005). As salespeople lose confidence in the organization's procedural integrity in protecting their interests, they may desire to restore balance by engaging in active opportunism such as selectively presenting or distorting information reported. Importantly, salespeople may react to perceived unfairness irrespective of the favorability of their own rewards (Barclay, Skarlicki, and Pugh 2005), which is corroborated by our results after accounting for salespeople's own levels of rewards received.

In summary, by integrating relevant boundary conditions into expectancy theory, this study demonstrates that top performer rewards are a double-edged sword capable of producing both positive and negative outcomes with respect to fellow salespeople's behavior and performance. When the sales organization employs behavior control or when the sales unit size is large, overall organizational justice is a critical boundary condition to maximize the positive effects of top performer rewards while keeping deleterious effects at bay.

\section{Managerial implications}

As sales organizations strive to retain their top performers with attractive financial compensation and formal recognition, companies also believe that salespeople can improve their skills and performance by learning from top performers (Ledingham, Kovac, and Simon 2006). While we confirm the generally positive effect of top performer rewards on fellow salespeople's skill improvement, our results also suggest that managers must be aware of the unintended negative consequences of top performer rewards that may likely be inflicted upon the sales 
organization under certain conditions. Top performer rewards do not always deliver the intended message to the sales staff, especially when the organization employs a behavior control system in which the manager actively directs, monitors, and evaluates salespeople's required selling activities. Despite the benefits that behavior control affords the firm (Anderson and Oliver 1987), it can also significantly compromise the positive effect of top performer rewards on perceived top performer customer relationship building competence, especially when overall organizational justice is perceived as low. When overall organizational justice is low and behavior control is employed, top performer rewards are more likely to be linked to perceived favoritism resulting in salesperson opportunism. Such a pattern is also observed in large sales units. Importantly, although perceived favoritism may have not actually occurred, erroneous attributions are often made and salespeople will act in accordance with their inferences (Teas and McElroy 1986). Therefore, an overall justice perception in the sales organization is critical if top performer rewards are expected to motivate fellow salespeople to improve their selling skills, especially when behavior control is employed in a large sales unit. Firms must carefully assess whether their sales environment is optimally suited to leverage the intended positive implications of top performer rewards among the sales staff.

\section{Limitations and future research directions}

This study is subject to some limitations. First, level-one data may be affected by common method bias as they came from the single source-the salesperson. Although post hoc analysis suggests that this is not likely a serious threat, future research can collect multisource or longitudinal level-one data for more definitive causal inferences. Second, our empirical context is the consumer division of financial investment firms. The extent to which our findings would apply in other sales settings (e.g., B2B product-based sales) cannot be assumed without further 
testing. Third, we collected data in Taiwan (a collectivist culture), which may have bolstered some of the proposed relationships in the model. Whether results are generalizable to more individualist cultural contexts remain to be seen.

Our research also points to directions for future research endeavors. First, we conceptualized behavior control based on Anderson and Oliver's (1987) seminal work by treating it as a global construct. A more refined concept of behavior control includes two qualitatively distinct constructs-activity control and capability control (Challagalla and Shervani 1996). While activity control specifies a set of activities and courses of action salespeople have to perform during the selling process, capability control allows for more flexibility by focusing on improving the salesperson's ability to effectively adapt to different customer encounters and situations (Miao and Evans 2013). Because we operationalized behavior control in line with activity control, the extent to which capability control can strengthen the link between top performer rewards and perceived top performer customer relationship building competence remains to be seen.

Second, we did not consider the top performer's characteristics in the model. For example, it is likely that the top performer has superior political skills (e.g., interpersonal influence, social astuteness), which enable the top salesperson to establish relational centrality and positional centrality (Bolander et al. 2015). Research has suggested that network ties can moderate fairness judgment (Arnold et al. 2009). Will these top performer-related network characteristics matter? How will they moderate fellow salesperson's perceptions?

Third, we examined overall organizational justice as a critical boundary condition in our model. Although overall justice provides a heuristic for salespeople to make attributional inferences, it is the sales manager that plays a proximal role in the daily interaction with and 
management of salespeople. It would be interesting to compare the relative impact of the sales manager's influence (e.g., trustworthiness) versus the organization-level characteristics (e.g., justice) especially when they differ. For example, when the sales manager is trustworthy yet the overall organization justice is considered to be low, how will the effect of top performer rewards differ relative to another scenario where the sales manager is not trustworthy yet the overall organizational justice is high? These important questions can only be answered by future research. 


\section{References}

Abosch, K. (2012). Companies frequently fail to differentiate performance. Report on Salary Surveys, $19(8), 11-12$.

Ahearne, M., Rapp, A., Hughes, D. E., \& Jindal, R. (2010). Managing sales force product perceptions and control systems in the success of new product introductions. Journal of Marketing Research, 47 (August), 764-776.

Ambrose, M. L. \& Schminke, M. (2009). The role of overall justice judgements in organizational justice research: A test of mediation. Journal of Applied Psychology, 94 (2), 491-500.

Anderson, J. C., \& Gerbing, D. W. (1988). Structural equation modeling in practice: A review and recommended two-step approach. Psychological Bulletin, 103(3), 411-423.

Anderson, E \& Oliver, R. L. (1987). Perspectives on behavior-based versus outcome-based salesforce control systems. Journal of Marketing, 51 (October), 76-88.

Aquino, K., Tripp, T. M., \& Bies, R. J. (2006). Getting even or moving on? Power, procedural justice, and types of offense as predictors of revenge, forgiveness, reconciliation, and avoidance in organizations. Journal of Applied Psychology, 91 (3), 653-668.

Arnold, T. J., Landry, T. D., Scheer, L. K., \& Stan, S. (2009). The role of equity and work environment in the formation of salesperson distributive fairness judgements. Journal of Personal Selling and Sales Management, 29 (1), 61-80.

Barclay, L. J., Skarlicki, D. P., \& Pugh, S. D. (2005). Exploring the role of emotions in injustice perceptions and retaliation. Journal of Applied Psychology, 90 (4), 629-643.

Bellizzi, J. A. \& Bristol, T. (2005). Supervising the unethical selling behavior of top sales performers: Assessing the impact of social desirability bias. Journal of Business Ethics, $57,377-388$.

Bobocel, D. R. (2013). Coping with unfair events constructively or destructively: The effects of overall justice and self-other orientation. Journal of Applied Psychology, 98 (5), 720731.

Bolander, W., Satornino, C. B., Hughes, D. E., \& Ferris, Gerald. (2015). Scocial networks within sales organizations: Their development and importance for salesperson performance. Journal of Marketing, 79 (November), 1-16.

Brislin, R. W. (1980). Translation and content analysis of oral and written materials. In H. C. Triandis \& J. W. Berry (Eds.), Handbook of Cross-Cultural Psychology (Vol. 2, pp. 389444). Boston: Allyn \& Bacon. 
Buchanan, A. (2002). Rewarding top performers - maximizing return on your compensation investment. Compensation \& Benefits Report, 16 (12), 8-9.

Carson, S. J. (2007). When to give up control of outsourced new product development. Journal of Marketing, 71(1), 49-66.

Challagalla, G. N. \& Shervani, T. A. (1996). Dimensions and types of supervisory control: effects on salesperson performance and satisfaction. Journal of Marketing, 60 (January), 89-105.

Chan, T. Y., Li, J., \& Pierce, L. (2014). Learning from peers: Knowledge transfer and sales force productivity growth. Marketing Science, 33 (4), 463-484.

Choi, N. H., Dixon, A. L., \& Jung, J. M. (2004). Dysfunctional behavior among sales representatives: The effect of supervisory trust, participation, and information controls. Journal of Personal Selling \& Sales Management, 24 (3), 181-198.

Churchill, G. A., Ford, N. M., Hartley, S. W., \& Walker, O. C. (1985). The determinants of salesperson performance: A meta-analysis. Journal of Marketing Research, 22 (May), 103-118.

Cowen, B. (2016). Caution: Superstar can hurt your contact center. www.communicoltd.com

Cowherd, D. M. \& Levine, D. L. (1992). Product quality and pay equity between lower-level employees and top management: An investigation of distributive justice theory. Administrative Science Quarterly, 37, 302-320.

Cravens, D. W., Ingram, T. N., LaForge, R. W., \& Young, C. E. (1993). Behavior-based and outcome-based salesforce control systems. Journal of Marketing, 57 (October), 47-59.

Cron, W. L., Dubinsky, A. J., \& Michaels, R. E. (1988). The influence of career stages on components of salesperson motivation. Journal of Marketing, 52 (January), 78-92.

DeConinck, J. B. \& Johnson, J. T. (2009). The effects of perceived supervisor support, perceived organizational support, and organizational justice on turnover among salespeople. Journal of Personal Selling \& Sales Management, 29 (4), 333-350.

Desai, V. (2015). Learning through the distribution of failures within an organization: Evidence from heart bypass surgery performance. Academy of Management Journal, 58 (4), 10321050 .

Evans, K. R., Margheim, L., \& Schlacter, J. L. (1982). A review of expectancy theory research in selling. Journal of Personal Selling and Sales Management, 2 (2), 33-40. 
Fang, E., Evans, K. R., \& Landry, T. D. (2005). Control systems' effect on attributional processes and sales outcomes: A cybernetic information-processing perspective. Journal of the Academy of Marketing Science, 33 (4), 553-574.

Fornell, C., \& Larcker, D. F. (1981). Evaluating structural equation models with unobservable variables and measurement error. Journal of Marketing Research, 18 (February), 39-50.

Gellerman, S. W. (1990). The test of a good salesperson. Harvard Business Review, 68 (3), 6469.

Green, T. \& Peloza, J. (2014). How do consumers infer corporate social responsibility? The role of organization size. Journal of Consumer Behavior, 13, 282-293.

Henderson, B. (2001). A manager's dilemma: Avoiding favoritism among employees. Health Care Collector: The Monthly Newsletter for Health Care Collectors, 15 (3), 9.

Huber, V. L., Podsakoff, P. M., \& Todor, W. D. (1986). An investigation of biasing factors in the attributions of subordinates and their supervisors. Journal of Business Research, 14, 8398.

Hughes, D. E., Bon, J. L., \& Rapp, A. (2013). Gaining and leveraging customer-based competitive intelligence: The pivotal role of social capital and salesperson adaptive selling skills. Journal of the Academy of Marketing Science, 41, 91-110.

Hunter, G. K. \& Perreault, W. D. (2007). Making sales technology effective. Journal of Marketing, 71 (January), 16-34.

Jelinek, R. \& Ahearne, M. (2006). The enemy within: Examining salesperson deviance and its determinants. Journal of Personality and Social Psychology, 26 (4), 327-344.

Johnston, W. J. \& Kim, K. Performance, attribution, and expectancy linkages in personal selling. Journal of Marketing, 58 (4), 68-81.f

Kim, D., Cavusgil, S. T., \& Calantone, R. J. (2006). Information system innovations and supply chain management: Channel relationships and firm performance. Journal of the Academy of Marketing Science, 34(1), 40-54.

Lam, S. K., Kraus, F., \& Ahearne, M. (2010). The diffusion of market orientation throughout the organization: A social learning theory perspective. Journal of Marketing, 74 (September), 61-79.

Ledingham, D., Kovac, M., \& Simon, H. L. (2006). The new science of sales force productivity. Harvard Business Review, 84 (9), 124-133.

Lehrer, J. (2010). The superstar effect. Wall Street Journal, 255 (77), pw1-w2. 
Miao, C. F., \& Evans, K. R. (2013). The interactive effects of sales control systems on salesperson performance: A job demands-resources perspective. Journal of the Academy of Marketing Science, 41, 73-90.

Miao, C. Fred, \& Evans, K. R. (2014). "Motivating industrial salesforce with sales control systems: An interactive perspective," Journal of Business Research, 67 (6), 1233-1242.

Offenberger, B. (2016). 44 reasons your salespeople may not be performing well. Security Distributing \& Marketing, 46 (8), 54.

Oliver, R. L. \& Anderson, E. (1994). An empirical test of the consequences of behavior- and outcome-based sales control systems. Journal of Marketing, 58 (October), 53-67.

Oliver, R. L. \& Anderson, E. (1995). Behavior- and outcome-based sales control systems: Evidence and consequences of pure-form and hybrid governance. Journal of Personal Selling \& Sales Management, 15 (4), 1-15.

Palmatier, R. W., Dant, R. P., Grewal, D., Evans, K. R. (2006). Factors influencing the effectiveness of relationship marketing: A meta-analysis. Journal of Marketing, 70 (October), 136-153.

Palmatier, R. W., Scheer, L. K., Houston, M. B., Evans, K. R., Gopalakrishna, S. (2007). Use of relationship marketing programs in building customer-salesperson and customer-firm relationships: Differential influences on financial outcomes. International Journal of Research in Marketing, 24, 210-223.

Pfeffer, J. (2001). Fighting the war for talent is hazardous to your organization's health. Organizational Dynamics, 29 (4), 248-259.

Plouffe, C. R., Hulland, J., \& Wachner, T. (2009). Customer-directed selling behaviors and performance: A comparison of existing perspectives. Journal of the Academy of Marketing Science, 37, 422-439.

Pullins, E. B. \& Fine, L. M. (2002). How the performance of mentoring activities affects the mentor's job outcomes. Journal of Personal Selling \& Sales Management, 22 (4), 259271.

Ramaswami, S. N. \& Singh, J. (2003). Antecedents and consequences of merit pay fairness for industrial salespeople. Journal of Marketing, 67 (October), 46-66.

Rentz, J. O., Shepherd, C. D., Tashchian, A., Dabholkar, P. A., \& Ladd, R. T. (2002). A measure of selling skills: Scale development and validation. Journal of Personal Selling and Sales Management, 22 (1), 13-21. 
Schnake, M. E. \& Dumler, M. P. (1989). Some unconventional thoughts on the use of punishment in organizations: Reward as punishment and punishment as reward. Journal of Social Behavior and Personality, 4 (1), 97-107.

Siemsen, E., Roth, A., \& Oliveira, P. (2010). Common method bias in regression models with linear, quadratic, and interaction effects. Organizational Research Methods, 13, 456-476.

Skarlicki, D. P. \& Folger, R. (1997). Retaliation in the workplace: The role of distributive, procedural, and interactional justice. Journal of Applied Psychology, 82 (3), 434-443.

Spiro, R.L. \& Weitz, B. A. (1990). Adaptive selling: Conceptualization, measurement, and nomological validity. Journal of Marketing Research 27 (February): 61-69.

Sujan, H., Weitz, B. A., \& Sujan, M. (1988). Increasing sales productivity by getting salespeople to work smarter. Journal of Personal Selling and Sales Management, 8 (2), 9-19.

Teas, R. K. \& McElroy, J. C. (1986). Causal attributions and expectancy estimates: A framework for understanding the dynamics of salesforce motivation. Journal of Marketing, 50 (January), 75-86.

Tyagi, P. K. (1982). Perceived organizational climate and the process of salesperson motivation. Journal of Marketing Research, 19 (May), 240-254.

Vroom, V. H. Work and Motivation. New York: John Wiley and Sons, 1964.

Zenger, T. R. (1992). Why do employers only reward extreme performance? Examining the relationships among performance, pay, and turnover. Administrative Science Quarterly, 37, 198-219. 


\section{Figure 1}

Effects of Top Performer Rewards: A Multi-level Investigation

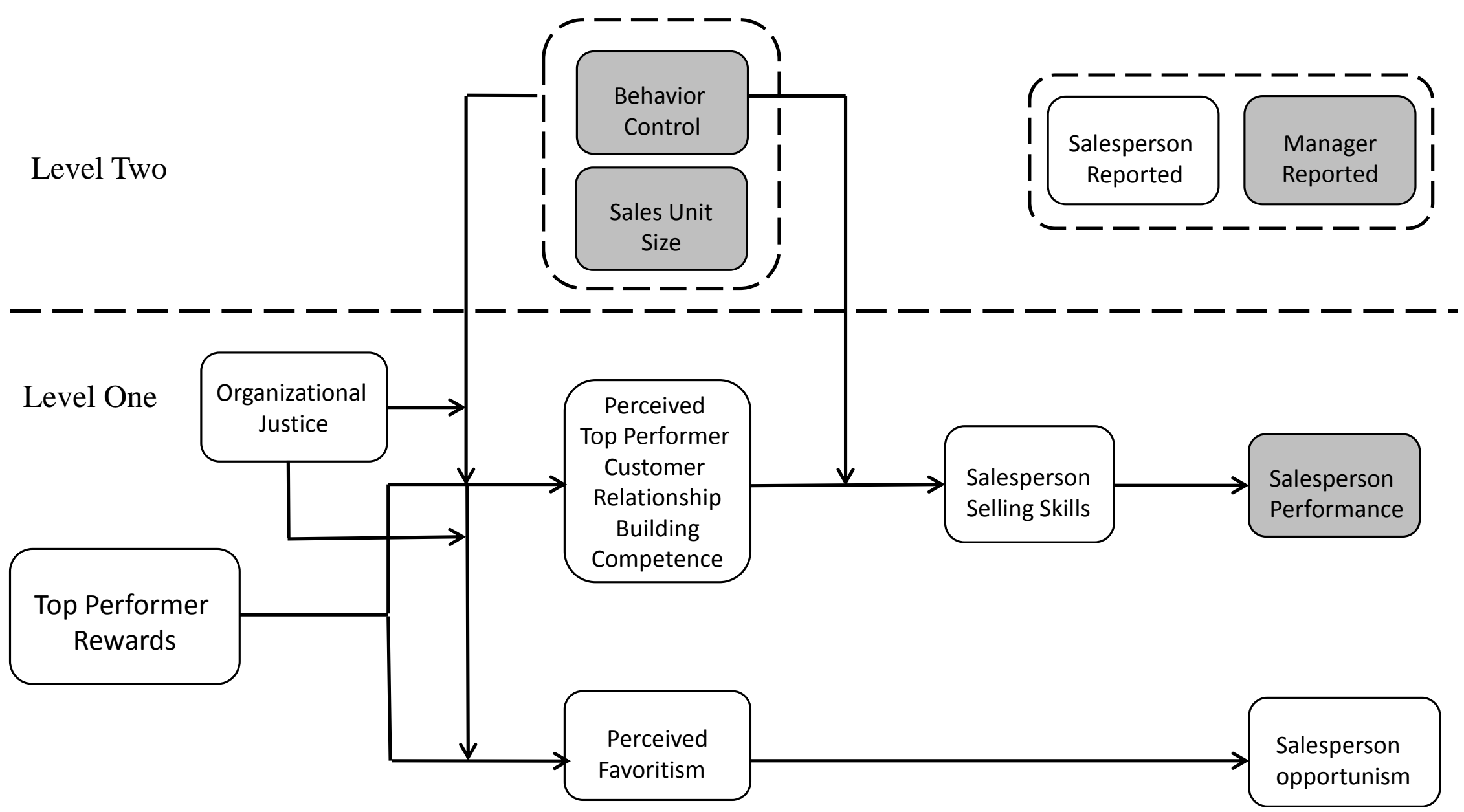


TABLE 1

Descriptive statistics and intercorrelations of study variables

\begin{tabular}{|c|c|c|c|c|c|c|c|c|c|c|c|c|c|c|c|}
\hline & $\mathrm{M}$ & SD & $\mathrm{AVE}^{\mathrm{a}}$ & 1 & 2 & J & 4 & J & 0 & 1 & o & y & 10 & 11 & 12 \\
\hline 1. Top performer rewards & 5.54 & .99 & .62 & .76 & & & & & & & & & & & \\
\hline 2. Top performer customer relationship building competence & 5.85 & .82 & .52 & $.46^{* *}$ & .83 & & & & & & & & & & \\
\hline 3. Favoritism & 4.19 & 1.48 & .83 & .08 & $-.17^{*}$ & .93 & & & & & & & & & \\
\hline 4. Salesperson selling skills & 5.00 & 1.01 & .79 & $.22^{* *}$ & $.21^{* *}$ & .01 & .92 & & & & & & & & \\
\hline 5. Salesperson opportunism & 4.12 & 1.18 & .52 & -.12 & -.10 & $.24^{* *}$ & -.01 & .83 & & & & & & & \\
\hline 6. Salesperson rewards & 4.41 & .99 & .77 & $.28^{* *}$ & $.22 * *$ & .06 & $.56^{* *}$ & -.10 & .86 & & & & & & \\
\hline 7. Organizational justice & 4.60 & 1.11 & .50 & $.27^{* *}$ & $.23^{* *}$ & $-.21^{* *}$ & $.25^{* *}$ & $-.43^{* *}$ & $.37 * *$ & .73 & & & & & \\
\hline 8. Behavior control & 4.87 & 1.05 & .59 & .13 & .07 & -.03 & -.06 & $.16^{*}$ & .02 & -.13 & .71 & & & & \\
\hline 9. Sales unit size & 10.9 & 12.9 & - & .02 & .09 & .06 & -.02 & -.01 & .06 & -.06 & .00 & - & & & \\
\hline 10. Salesperson experience & 6.95 & 4.80 & - & .01 & -.04 & .04 & $.18^{* *}$ & -.04 & $.19 * *$ & .08 & $-.14^{*}$ & .06 & - & & \\
\hline 11. Salesperson age & 35.33 & 7.47 & - & .02 & .02 & -.00 & .04 & -.10 & .05 & .05 & -.12 & .01 & $.57^{* *}$ & - & \\
\hline 12. Salesperson performance & 4.60 & 1.34 & .80 & .12 & .08 & .07 & $.21^{* *}$ & -.05 & $.34^{* *}$ & .07 & .10 & .01 & .01 & .03 & .92 \\
\hline
\end{tabular}

12. Salesperson performance

$\begin{array}{lll}4.60 & 134 & 80\end{array}$

* $\mathrm{p}<.05$

${ }^{a}$ AVEs of salespeople-reported constructs are CMV-adjusted

Cronbach's alphas appear on the diagonal. 
Table 2. Model comparison and results ${ }^{a}$

Top performer rewards $\longrightarrow$ top performer customer relationship building competence

Organizational justice $\longrightarrow$ top performer customer relationship building competence

Salesperson rewards $\longrightarrow$ top performer customer relationship building competence

Salesperson age $\longrightarrow$ top performer customer relationship building competence

Salesperson experience $\longrightarrow$ top performer customer relationship building competence

Top performer rewards $\longrightarrow$ favoritism

Organizational justice $\longrightarrow$ favoritism

Salesperson rewards $\longrightarrow$ favoritism

Salesperson age $\longrightarrow$ favoritism

Salesperson experience $\longrightarrow$ favoritism

Top performer customer relationship building competence $\longrightarrow$ salesperson selling skills

Salesperson age $\longrightarrow$ salesperson selling skills

Salesperson experience $\longrightarrow$ salesperson selling skills

Favoritism $\longrightarrow$ salesperson opportunism

Salesperson age $\longrightarrow$ salesperson opportunism

Salesperson experience $\longrightarrow$ salesperson opportunism

Salesperson selling skills $\longrightarrow$ salesperson performance

Salesperson age $\longrightarrow$ salesperson performance

Salesperson experience $\longrightarrow$ salesperson performance

Behavior control $\longrightarrow$ top performer customer relationship building competence

Behavior control $\longrightarrow$ favoritism

Behavior control $\longrightarrow$ salesperson selling skills

Sales unit size $\longrightarrow$ top performer customer relationship building competence

Sales unit size $\longrightarrow$ favoritism
Model 1: Baseline model Model 2: Hypothesized Model 3: Best fitting (main effects only) (interactive effects) model

$40 * *$

$.42 * *$

05

$14 *$

.01

$.14^{*}$

.05

$-.10 *$

.07

$-.12 *$

.14

$-.16^{*}$

.001

$-.14^{*}$

.10

$.27 * *$

$-.11 *$

$.22 * *$

$.29 * *$

$-.10$

$-.03$

$22 * *$

.02

$-.02$

.01

$-.10$

$-.08$

$.09 *$

.05
.01

$.14 *$

.05

$-.10 *$

.06

$-.10$

.06

$-.09$

.07

$.24 * *$

$-.13^{*}$

$.22^{* *}$

.23*

$-.10$

.04

$22 * *$

$-.02$

$-.02$

$-.003$

$-.08$

$-.08$

.06 
Table 2 Continued

Top performer rewards $\mathrm{X}$ behavior control $\longrightarrow$ top performer customer relationship building competence

Organizational justice $\mathrm{x}$ behavior control $\longrightarrow$ top performer customer relationship building competence

Top performer rewards $X$ organizational justice $\longrightarrow$ top performer customer relationship building competence

Top performer rewards $X$ behavior control

$\longrightarrow$ favoritism

Organizational justice $X$ behavior control $\longrightarrow$ favoritism

Top performer rewards $X$ organizational justice $\longrightarrow$ favoritism

Top performer rewards $X$ sales unit size $\longrightarrow$ top performer customer relationship building competence

Organizational justice $\mathrm{x}$ sales unit size $\longrightarrow$ top performer customer relationship building competence

Top performer rewards $X$ sales unit size $\longrightarrow$ favoritism

Organizational justice $X$ sales unit size $\longrightarrow$ favoritism

Top performer rewards $X$ organizational justice $\mathrm{x}$ behavior control $\longrightarrow$ top performer customer relationship building competence

Top performer rewards $\mathrm{X}$ organizational justice $\mathrm{x}$ behavior control

Top performer rewards $\mathrm{X}$ organizational justice $\mathrm{x}$ sales unit size $\longrightarrow$ top performer customer relationship building competence

Top performer rewards $X$ organizational justice $x$ sales unit size $\longrightarrow$ favoritism

Top performer customer relationship building competence $\mathrm{X}$ behavior control $\longrightarrow$ salesperson selling skills

Behavior control $\longrightarrow$ salesperson opportunism

Sales unit size $\longrightarrow$ salesperson selling skills

Organizational justice $\longrightarrow$ salesperson opportunism

Log-likelihood

Chi-square difference ( $\Delta$ d.f.)

d.f.

$\mathrm{N}$

Clusters

\begin{tabular}{lll}
- & $-.17^{*}$ & $-.17^{*}$ \\
- & .10 & .10 \\
- & .03 & .04 \\
- & .01 & .01 \\
- & -.03 & -.02 \\
- & $-.22^{* *}$ & $-.22^{*}$ \\
- & .04 & .05 \\
- & -.07 & -.08 \\
- & -.08 & -.09 \\
- & .08 & .09 \\
- & & \\
& $.09 *$ & $.09^{*}$ \\
- & $-.14^{*}$ & $-.15^{*}$ \\
- & & \\
- & .05 & .05 \\
- & $-.14^{* *}$ & $-.14^{* *}$ \\
- & $-.12^{*}$ & $-.12^{*}$ \\
- & - & $.10^{*}$ \\
- & - & $-.06^{*}$ \\
- & - & $-.35^{* *}$ \\
-1438.261 & -1420.237 & -1403.244 \\
- & $48.65(22)^{* *}$ & $38.58(7)^{* *}$ \\
41 & 63 & 70 \\
212 & 212 & 212 \\
71 & 71 & 71 \\
\hline
\end{tabular}

$* p<.05 ; * * p<.01$

anstandardized path coefficients 


\section{Figure 2}

A. Interactive effects of organizational justice, top performer rewards, and behavior control on perceived top performer customer relationship building competence
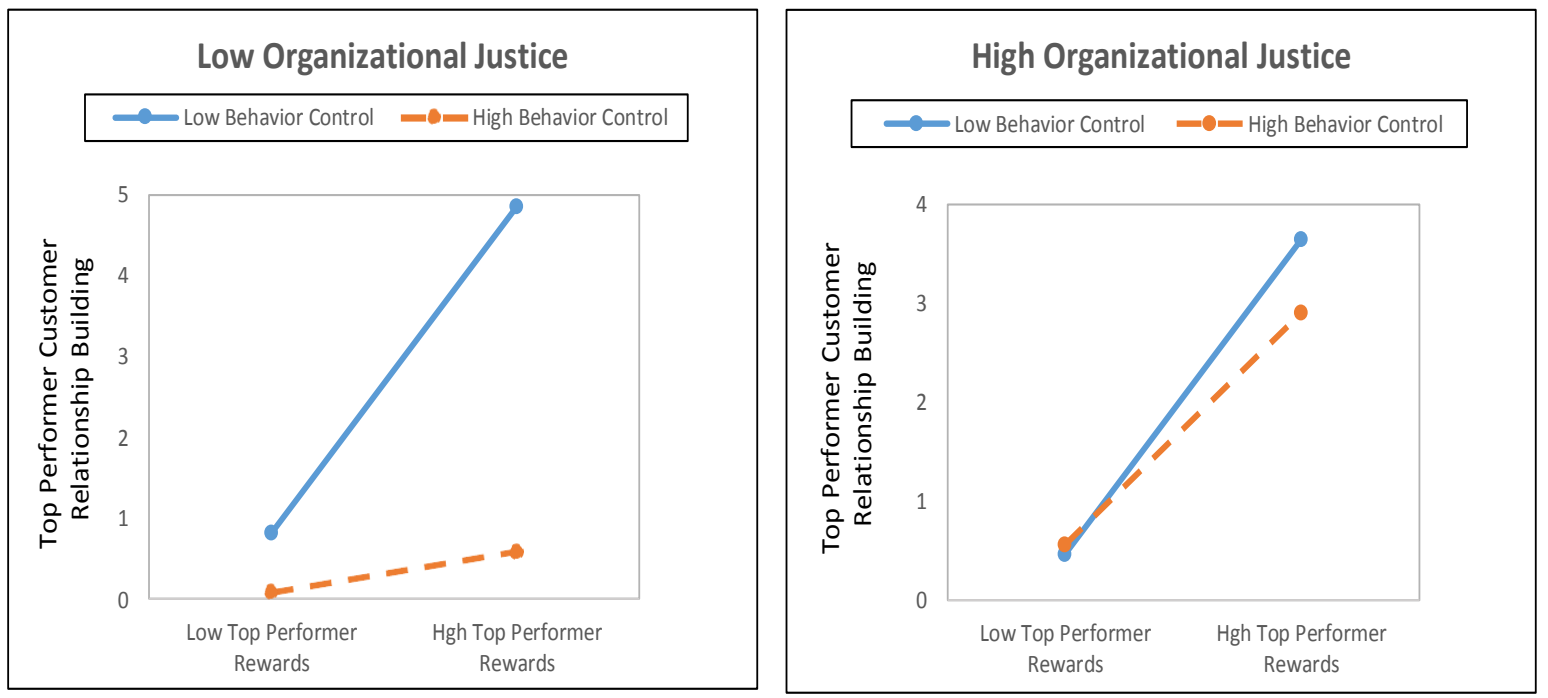
B. Interactive effects of organizational justice, top performer rewards, and behavior control on perceived top performer favoritism
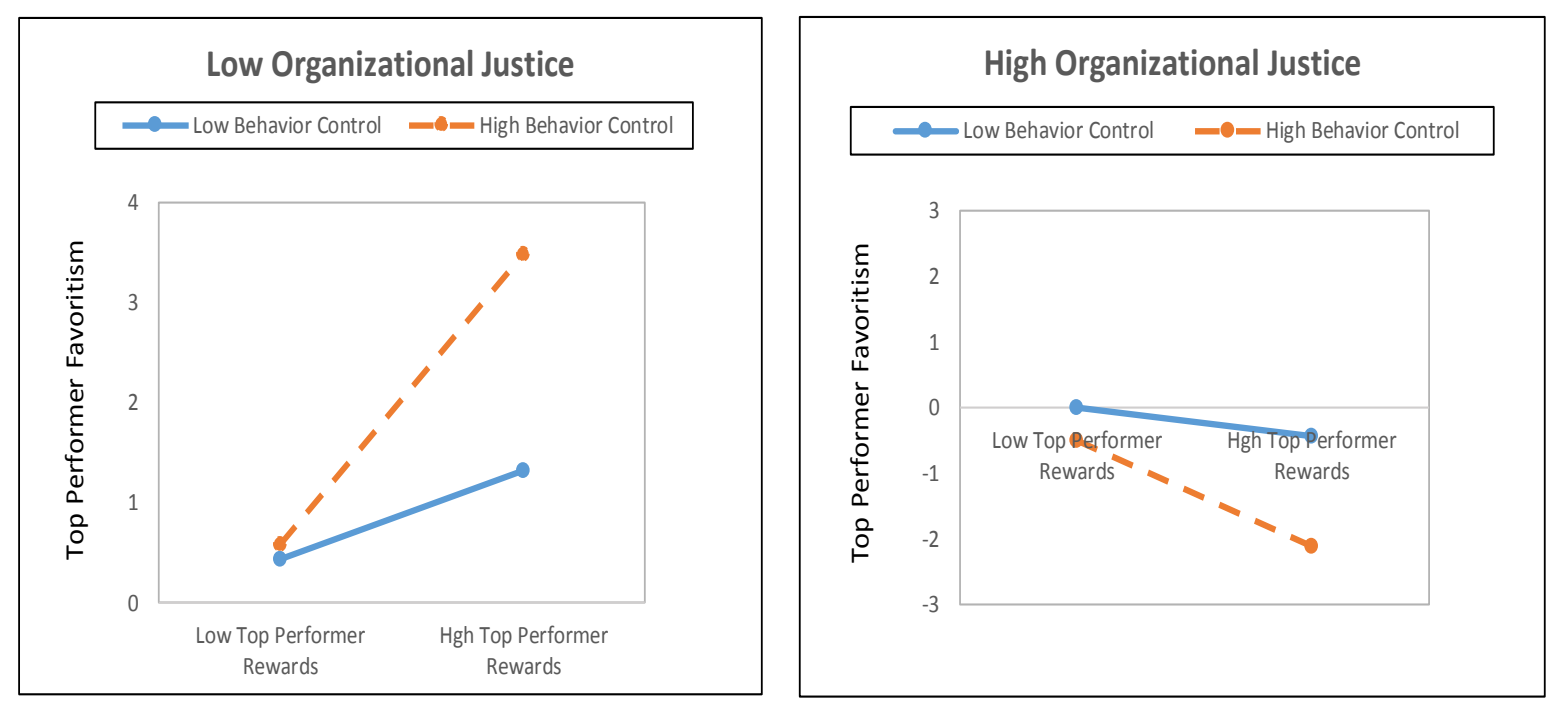

$\overline{\text { C. Interactive effects of organizational justice, top performer rewards, and sales unit size on perceived }}$ top performer favoritism
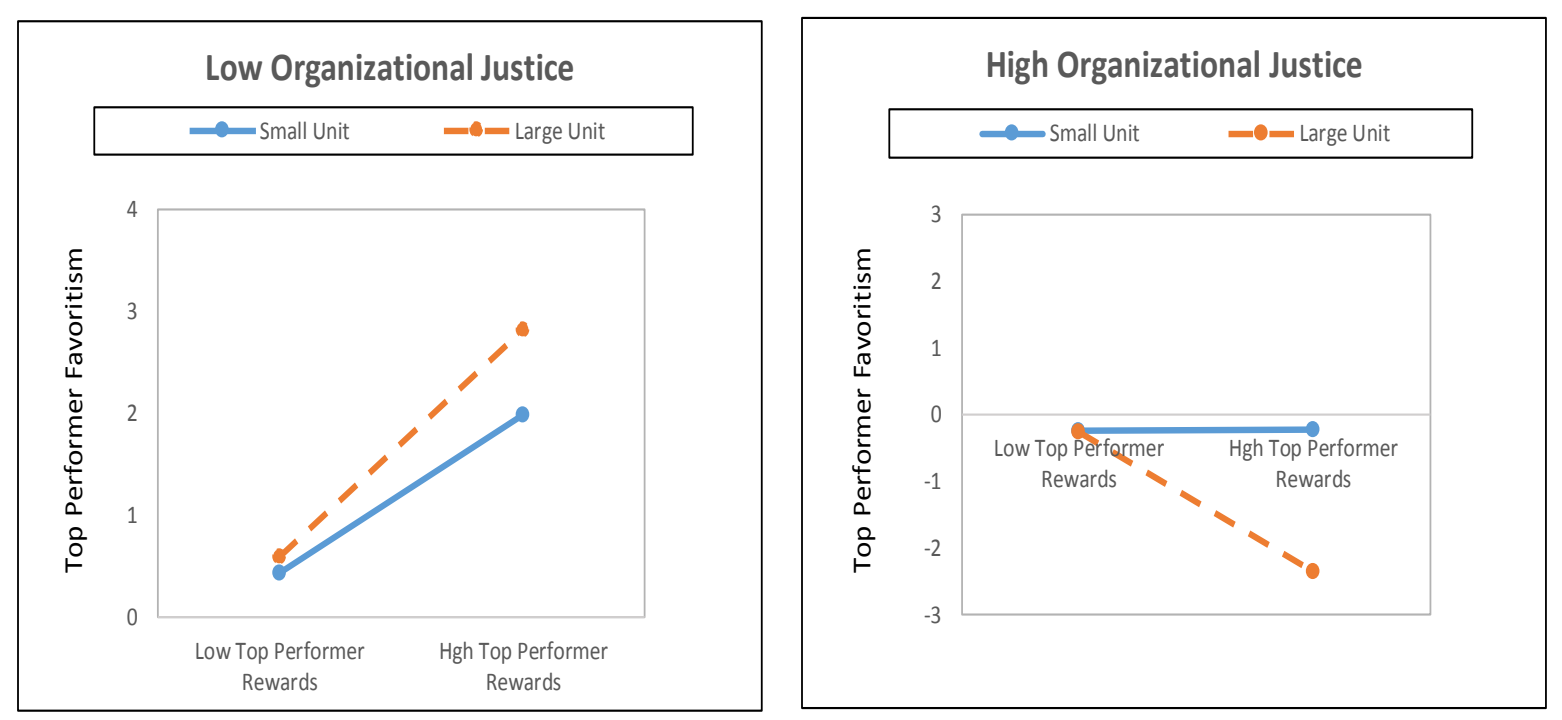


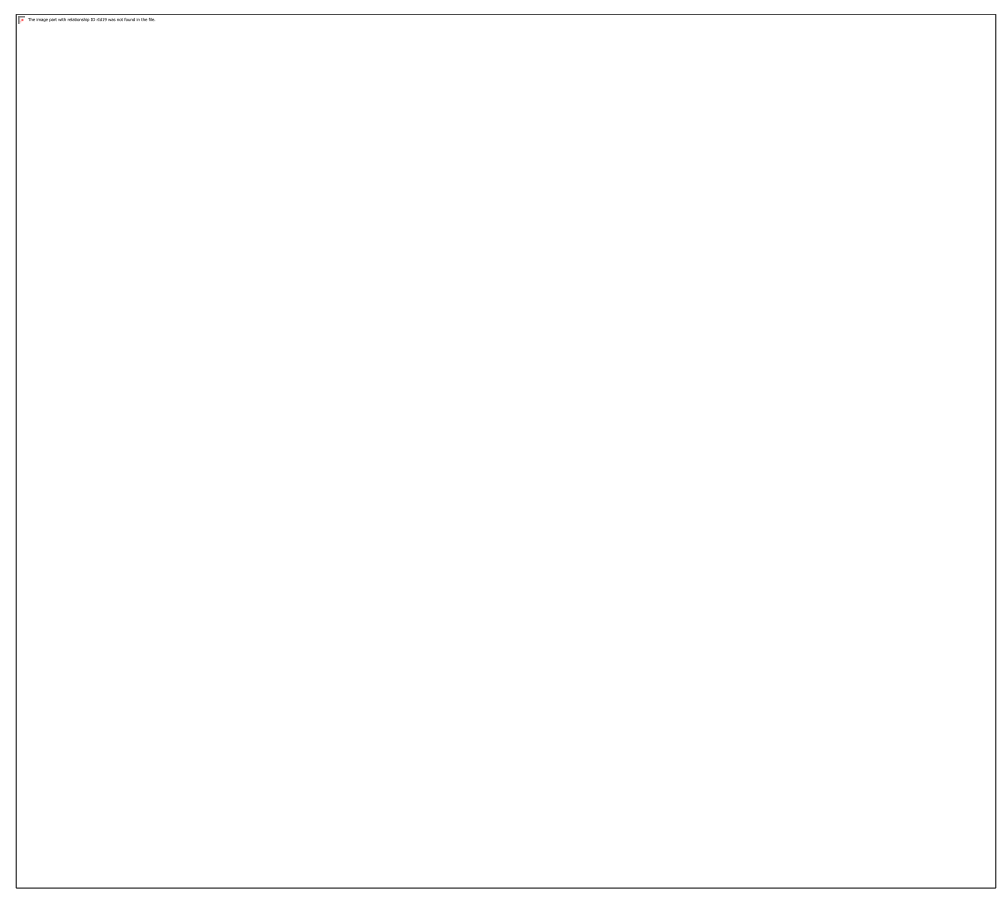




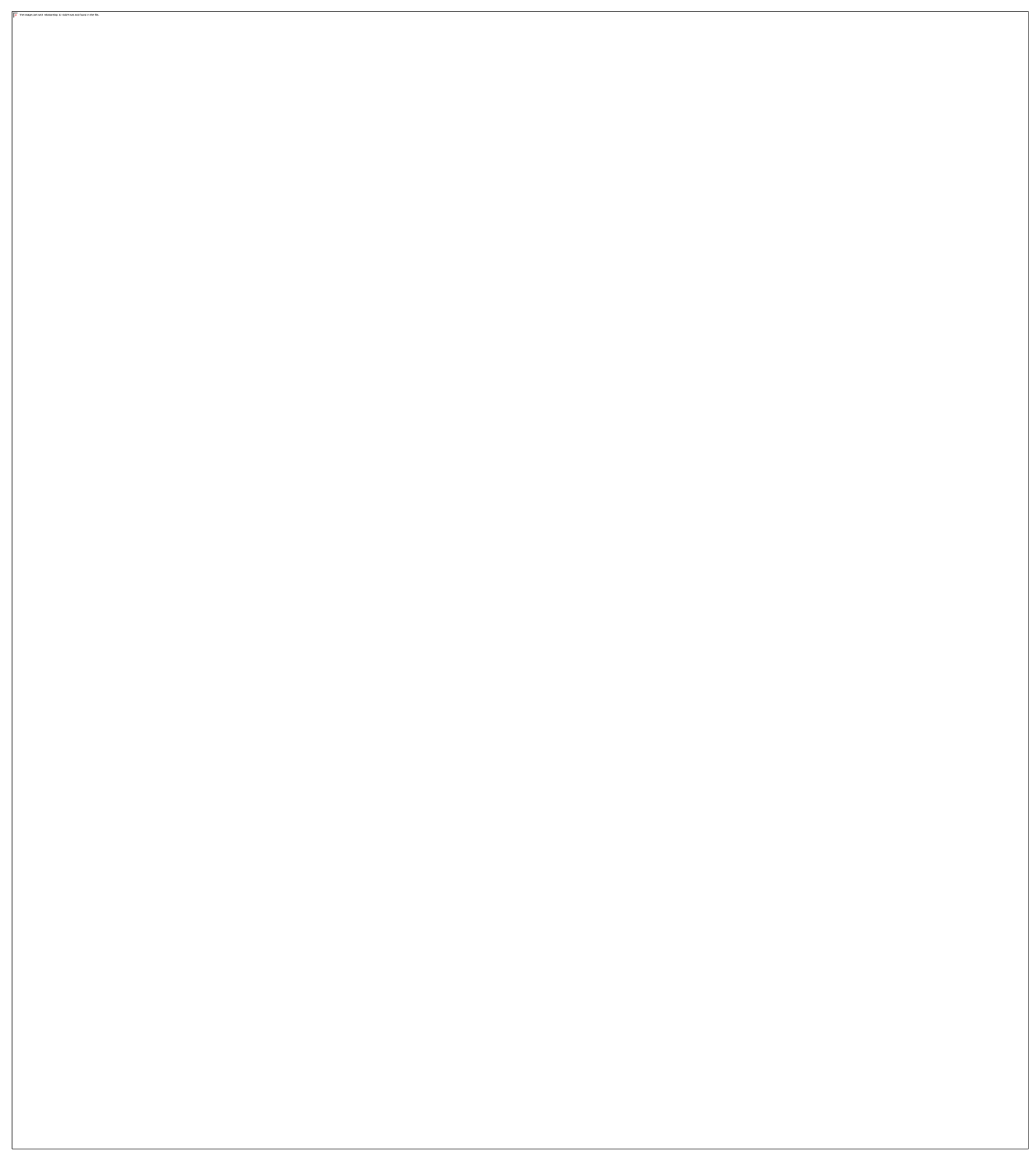

